\title{
Acute respiratory infection due to Mycoplasma pneumoniae: current status of diagnostic methods
}

\author{
K. Loens • H. Goossens • M. Ieven
}

Received: 16 March 2010 / Accepted: 18 May 2010/Published online: 6 June 2010

(C) Springer-Verlag 2010

\begin{abstract}
Because of the absence of well-standardized both in-house and FDA-approved commercially available diagnostic tests, the reliable diagnosis of respiratory infection due to Mycoplasma pneumoniae remains difficult. In addition, no formal external quality assessment schemes which would allow to conclude about the performance of M. pneumoniae diagnostic tests exist. In this review, the current state of knowledge of $M$. pneumoniae-associated respiratory infections in the context of epidemiological studies published during the past 5 years is discussed, with particular emphasis on the diagnostic strategies used and their impact on results. The role of M. pneumoniae as a cause of respiratory tract infections (RTIs) differs from study to study due to geographical and epidemiological differences, as well as to the application of different diagnostic techniques and criteria used.
\end{abstract}

\section{Introduction}

In 2003, we already stated that proper validation and standardization of nucleic acid amplification techniques (NAATs) are often lacking, and that the different methods used must be compared in order to define the most sensitive and specific tests [1]. This is similar for existing serological

Submitted to: The European Journal of Clinical Microbiology and Infectious Diseases

Electronic supplementary material The online version of this article (doi:10.1007/s10096-010-0975-2) contains supplementary material, which is available to authorized users.

K. Loens $(\square) \cdot H$. Goossens $\cdot M$. Ieven

Department of Microbiology, Vaccine and Infectious Disease

Institute (VIDI), University of Antwerp,

Antwerp, Belgium

e-mail: Katherine.loens@ua.ac.be tests and other new diagnostic tests as well. Studies comparing different methods still remain to be undertaken and will be critically important for the development of a standardized test for clinical laboratories.

Mycoplasma pneumoniae belongs to the class of the Mollicutes and has been associated with a wide variety of acute and chronic diseases. Respiratory tract infections (RTIs) with M. pneumoniae occur worldwide and in all age groups.

Serological methods, in particular, such as the complement fixation test (CFT) and enzyme immunoassays (EIAs), are most widely used to diagnose an M. pneumoniae infection. The application of polymerase chain reaction (PCR) is more and more often accepted as a rapid diagnostic test, since culture is too slow and too insensitive to be therapeutically relevant. Only a few of the currently available NAATs have been extensively validated against culture, which remains the reference standard, despite its low sensitivity and variable yield, depending on the specimens tested and the isolation protocols used. The sensitivity of NAATs is almost always superior to that of the traditional procedures, and they are more and more often considered as the "new gold standard". However, different studies have used not only different diagnostic tools or combinations thereof, but also different diagnostic criteria for making a diagnosis of an infection, thereby, making comparison between studies difficult. Most importantly, the lack of standardization has resulted in a wide variation of interlaboratory test performance, even when using the same test and criteria [2]. In an effort to standardize diagnostic assays for $C$. pneumoniae, recommendations have been published by the US Centers for Disease Control and Prevention (CDC) and the Canadian Laboratory Centre for Disease Control in 2001 [3]. However, no such recommendations exist for standardizing the diagnostic approach for M. pneumoniae. The epidemi- 
ology of $M$. pneumoniae-associated respiratory infections in studies performed all over the world for the purpose of examining the current state of knowledge of $M$. pneumoniae diagnostics since the publication of the 2003 minireview [1] was reviewed.

\section{Epidemiology of respiratory infection due to M. pneumoniae}

Varying with the population studied and diagnostic methods used, in studies published during the 1990s, in 6 to $>30 \%$ of lower respiratory tract infections (LRTIs), an association was found with $M$. pneumoniae [4-6]. Over 50 additional studies have been published about $M$. pneumoniae-associated LRTI since 2003. Data from selected studies chosen to represent different populations from around the world are summarized in Tables 1 and 2. As shown in these tables, the proportion of LRTI in children and adults, including community-acquired pneumonia, associated with $M$. pneumoniae infection during the past 5 years has ranged from 0 to $66.7 \%[7,8]$, varying with age and the geographic location of the population examined and the diagnostic methods used. In a lot of studies, the diagnosis of $M$. pneumoniae was based on serology alone [7, 9-11]; some used a PCR assay alone [8, $12,13]$ or at least one serological test and a PCR assay [14-20]. Only a limited number of studies used culture in combination with a serological test and/or PCR assay [2125] and three studies applied two different PCR assays [26-28]. Furthermore, there was a high degree of heterogeneity from study to study in the serological methods and criteria used. These are not necessarily interchangeable. In some studies, no data were presented on the type of assay and the criteria used, thereby, making it difficult, if not impossible, to compare results from one study to another.

One example is a prospective study of the incidence and etiology of community-acquired pneumonia in hospitalized adult patients [29] published in 1999. The researchers used serological methods and PCR for the diagnosis of an $M$. pneumoniae infection. The following serological criteria were used: a 4-fold rise or seroconversion in IgG- and/or an IgM-positive titer for M. pneumoniae. Fourteen percent of the patients were thought to have serological evidence of $M$. pneumoniae infection, but no information was provided on the serological method used. Furthermore, the study had no control subjects, and because of their absence, the significance of the reported seroprevalence of the patient group cannot be known. Background rates of seropositivity can be very high in some adult populations, ranging from 36 to $93 \%$ for $\operatorname{IgG}$ and ranging from 0 to $51 \%$ for $\operatorname{IgM}$, depending on the assay used [30].
Another example is the study of Oosterheert et al. [8]. In a randomized controlled trial, nasopharyngeal and oropharyngeal swab specimens from patients admitted for antibiotic treatment of LRTIs were evaluated by means of real-time PCR for respiratory viruses and atypical pathogens, as well as by conventional diagnostic procedures for virus detection. No details on the real-time PCR were given, although no $M$. pneumoniae-positive patient results were identified. No other methods were used in this study to confirm the negative results.

In general, in more recent studies using PCR assays, lower rates of $M$. pneumoniae-associated LRTI have been reported than in studies using serological testing (Tables 1 and 2). During a community outbreak of $M$. pneumoniae, Nilsson et al. [28] compared semi-nested and real-time PCR of oropharyngeal swabs with serology for the diagnosis of M. pneumoniae infections at different time points after the onset of disease. M. pneumoniae was diagnosed in 48/164 patients with a respiratory tract infection. Forty-five $(29 \%)$ were PCR-positive, whereas a significant rise in IgG titer or IgM antibodies was detected in 44/154 (27\%) subjects. Although the authors found that persistence of $M$. pneumoniae DNA in the throat was common and could be present for up to 7 weeks after the onset of disease, they concluded that PCR was superior to serology for the diagnosis of an $M$. pneumoniae infection during the early phase of infection. When examining 73 children with RTIs for $M$. pneumoniae by real-time PCR and two serological assays (a passive agglutination test and the ImmunoCard assay), Otomo et al. [31] confirmed the results of Nilsson et al. [28]. They found sensitivities of $100 \%$ and $33.3 \%$ and specificities of $100 \%$ and $82.1 \%$ for PCR and the ImmunoCard assay, respectively. According to the authors, real-time PCR or a related molecular assay is suitable for rapid diagnosis as a first screening test. These data confirmed the lack of correlation of serological methods with culture and/or PCR assays reported in earlier studies [1].

The epidemiological data emerging from pediatric studies have revealed similar inconsistencies of the methods and criteria used to make a diagnosis of an acute $M$. pneumoniae infection (Table 2). Examples include the use of single IgG titers by some studies (Table 2). A more specific example is a small uncontrolled pediatric study in Turkey [17] collecting nasopharyngeal samples for the PCR detection of $M$. pneumoniae DNA and blood for serology on the first admission to the hospital. However, they did not specify the PCR test applied, and although blood was only collected once (on hospital admission), serological diagnosis was made according to the materials and methods section by demonstrating an increment of $\operatorname{IgM}$ greater than $1 / 10$ and a 4-fold increase in IgG with enzyme-linked immunosorbent assay (ELISA). No positive case definition 


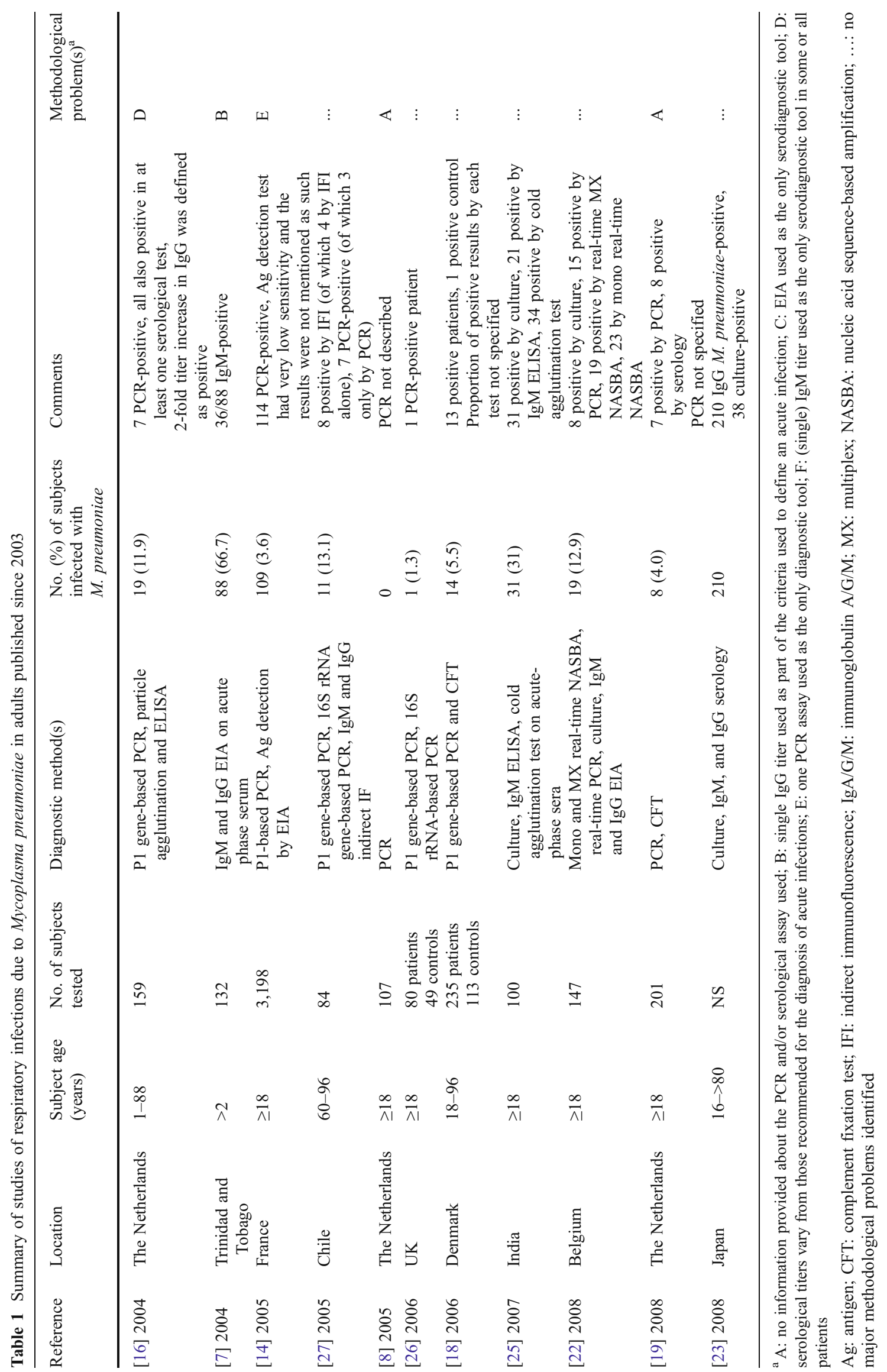




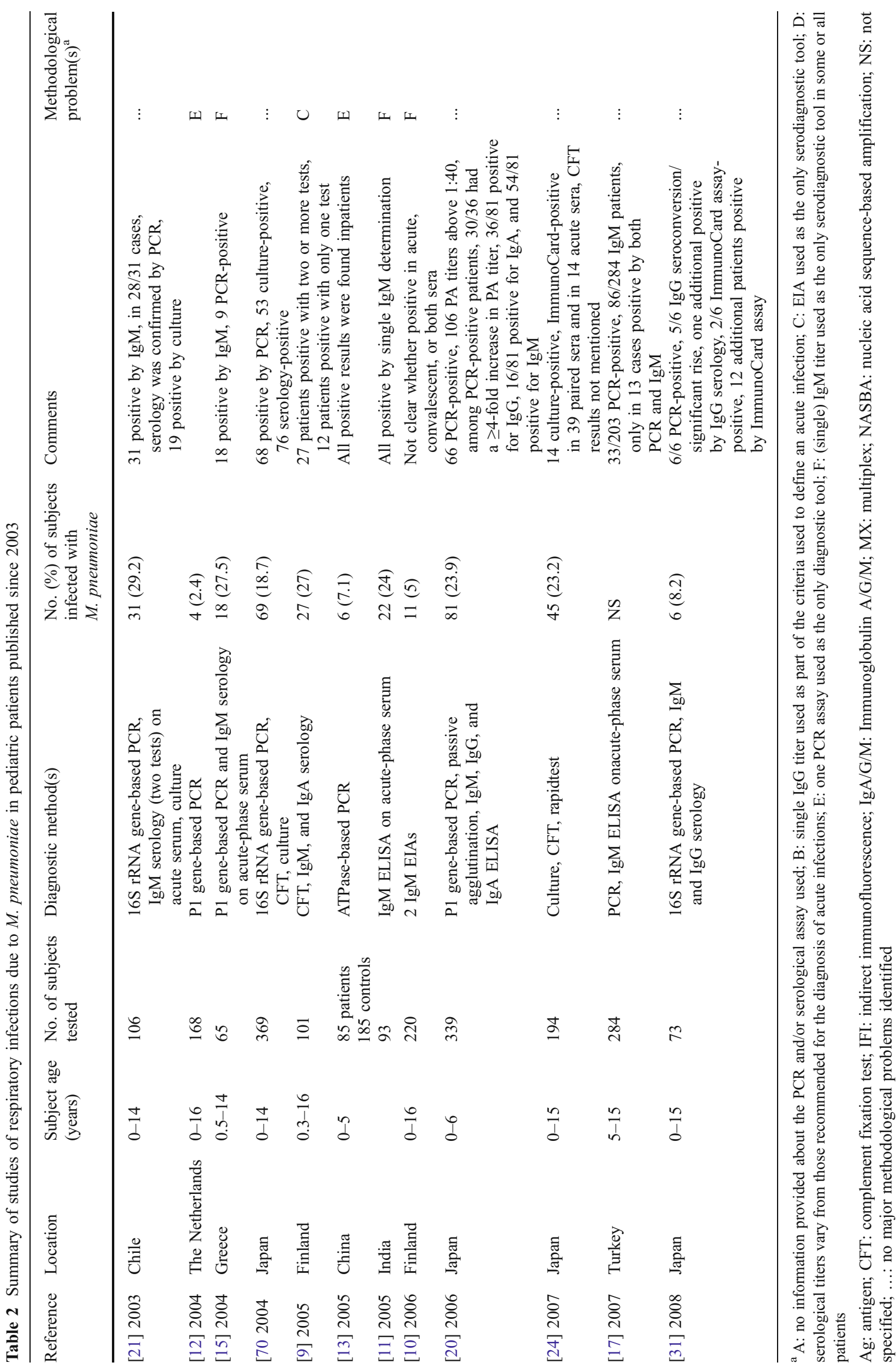


was mentioned either. The authors concluded that serological tests were more sensitive and specific than PCR, since the false-positive ratio for PCR was $16.2 \%$. Another small uncontrolled pediatric study in Dallas, Texas [32], identified M. pneumoniae as the cause of infection in $14 \%$ of patients with pneumonia. The center applied an ELISA for serological testing and used a 4-fold increase of IgG or single IgM titers of $\geq 1: 10$ as evidence of acute infection. However, they did not specify the proportion of positive results by the different antibody classes and no information on the ELISA was presented.

The true role of $M$. pneumoniae in RTIs remains a challenge given the wide variations of data from studies with equally wide variation of and lack of standardized diagnostic methods.

\section{Serology}

The serologic measurement of specific antibody responses has limited application for an etiologic diagnosis of an $M$. pneumoniae infection because diagnostic results are only available retrospectively.

A great number of antigen preparations have been proposed: whole organisms, protein fractions, glycoprotein fractions, recombinant antigens. Some commercialized assays lack both sensitivity and specificity, emphasizing the need for more validation and quality control [30, 33-35].

The sensitivity of the serological assays depends on whether the first serum sample is collected early or late after the onset of disease and on the availability of paired sera, since for an accurate diagnosis to be made, paired serum samples are required, with a 4-fold rise in titer appearing after three to four weeks after the onset of disease [36]. In practice, however, often, only one serum sample, from the acute-phase of the illness, is available or the two samples are collected within a too short time interval to detect a titer rise. Solitary high IgG titers have no diagnostic meaning for an acute infection, since the moment of the seroconversion is unknown and necessarily took place some time before the illness under observation started. Single high titers, for which a cut-off value has to be determined by a local evaluation, are useful only in prevalence studies among population groups.

Since IgM antibodies appear earlier than IgG antibodies, the detection of $\operatorname{IgM}$ in serum is a widely used approach for the early serologic diagnosis of an $M$. pneumoniae infection, especially in children. It should be realized that IgM antibodies are often not produced in children under 6 months of age, in a proportion of primary infections and during reinfections. A single IgM measurement may detect an acute infection with higher sensitivity if the test is performed after at least 7 days following the onset of disease [37]. In some patients, IgM antibodies appear even later [38]. Ozaki et al. [24] found that a single assay using the IgM ImmunoCard (Meridian Biosciences) had a sensitivity of $31.8 \%$ for the detection of an acute $M$. pneumoniae infection, which increased to $88.6 \%$ when paired sera were analyzed from seropositive children with pneumonia. Furthermore, an elevated IgM may persist for months after the acute infection [39]. IgM tests are usually less sensitive and specific than 4-fold changes in antibody titers between paired specimens separated by several weeks [40].

It has been reported that the detection of IgA-specific antibody seems to be a good indicator of a recent $M$. pneumoniae infection in both children and adults [41-43]. On the other hand, when evaluating the Medac IgM, IgG, and IgA assay on 159 serum samples from 113 patients with acute RTIs, Narita [44] did not find a significant advantage of detecting IgA in children.

Talkington et al. [35] compared eight commercial EIAs (two single-use EIAs and six plate-type EIAs) for the detection of specific $\operatorname{IgM} / \operatorname{IgG}$ antibodies, using paired serum samples from 51 patients with a confirmed $M$. pneumoniae infection and a positive complement fixation test (CFT). The results from acute-phase sera ranged from $14 \%$ ImmunoWELL IgM-positive to $45 \%$ positive by Zeus IgG EIA. When both the acute-phase and convalescent phase serum samples were analyzed, positive results ranged from $39 \%$ by the ImmunoWELL IgM assay to $88 \%$ positive by the Remel IgG-IgM EIA. In their study, the single-use EIAs proved to be more reliable than the platetype EIAs. Beersma et al. [30] evaluated the sensitivity and specificity of 12 assays for the detection of $M$. pneumoniae IgM and IgG, as well as the CFT. Some of the assays had a low sensitivity (Novum and ImmunoCard IgM), while the best performances in terms of sensitivity and specificity were recorded for ANILab systems (77 and 92\%, respectively) and the CFT (65 and 97\%, respectively). Petitjean et al. [34] found similar IgM sensitivities with four $M$. pneumoniae tests in children: between 89 and $92 \%$, but wide variations in adults: Platelia and BMD 16\%, Biotest $50 \%$ and Sorin $58 \%$. The specificities of the tests were 100 , 90,65 , and $25 \%$ respectively. The latter two IgM tests cannot, thus, be used for diagnosis. The sensitivities of the IgG tests in children varied between 52 and $78 \%$. The sensitivities for the IgG tests in adults were comparable: between 89 and $92 \%$. When comparing four IgM-, IgG-, and IgA-specific EIAs in sera from 504 blood donors and 102 patients with infections not caused by M. pneumoniae, Csángó et al. [45] reported the detection frequencies of IgM in blood donors varying between 2.8 and $16 \%$ and in patients between 9.8 and $42.2 \%$. IgA was detected in 22.8 to $68.5 \%$ of blood donor sera and in 53.8 to $100 \%$ of 
patients, illustrating again that the use of some serological kits may lead to a serious overdiagnosis of $M$. pneumoniae infections. Finally, Nir-Paz et al. [33] compared eight commercially available tests for $M$. pneumoniae using 204 single sera from healthy individuals. The study showed that age was associated with test positivity in healthy individuals, with the IgM peaking at primary/ secondary school age, and declining thereafter, while $\operatorname{IgG}$ rose progressively into adulthood. The high IgM positivity in these age groups casts doubt on the suggestion that combining IgM tests with amplification-based tests in the pediatric population might be of benefit $[6,46,47]$. Interassay agreement was poor. The study confirmed that single serum serology is unsuitable for the diagnosis of $M$. pneumoniae infection, and that commercially available tests need further improvement.

In conclusion, serologic tests can never offer an early diagnosis and are, therefore, an epidemiological than a diagnostic tool. The clinical significance of a serologic test, for both IgM and IgG, should be defined by studies of patients with a documented infection and for whom detailed information concerning the time lapses between the onset of disease and the collection of the serum specimens are known.

\section{Culture}

M. pneumoniae was first recovered on a medium devised by Hayflick in which PPLO agar [48] was supplemented with a fresh yeast extract preparation of Edward [49] and $20 \%$ horse serum. However, M. pneumoniae grows slowly, so cultures may require up to 6 weeks to become positive. Although the culture of $M$. pneumoniae is still considered to be the gold standard, it is seldomly performed as a diagnostic test.

Culture is, and will remain, essential for further biological and molecular characterization of clinical isolates (including antibiotic resistance studies); however, its use as a routine diagnostic tool is suboptimal.

\section{PCR}

Over the last 20 years, NAATs have become a major tool for the detection of micro-organisms, for diagnostic testing, and for research purposes in the field of infectious diseases. NAATs offer significant sensitivity and speed compared to culture and do not require the presence of viable organisms. Diagnostic testing for micro-organisms based on NAATs has become increasingly complex and the field is changing and expanding rapidly. Thus, an NAAT established 10 years ago and designed with the best information and knowledge available at that time may not necessarily be state-of-the-art today.

Validated commercially available FDA-cleared assays exist only for a limited number of organisms and not for the detection of M. pneumoniae in respiratory or other specimens. There are also a number of so-called analyte-specific reagents commercially available. Besides these standardized kits, the use of NAATs for research purposes kits and in-house developed NAATs has expanded tremendously. The assays range from those that are well validated to those that are not. Carefully reading many of these publications reveals that, often, little or no information is provided on the validation of the NAATs applied. Yet, these assays are frequently used and cited in the literature.

At the time of the 2003 minireview [1], there were 34 published in-house NAATs for the detection of M. pneumoniae DNA or RNA. However, validation was primarily analytical; none of these assays were extensively evaluated using clinical specimens from well-defined patient populations from a wide geographic area. Since then, an additional 27 assays have been described (Tables 3 and 4). There is a great variation of the methods used from study to study, including variability of target (P1 gene, 16S rRNA, ATPase gene, parE gene, tuf gene; monoplex versus multiplex targets) and of NAAT (conventional, nested, and real-time; RNA vs. DNA targets; and PCR and nucleic acid sequencebased amplification technologies) and detection formats (agarose gel electrophoresis, SYBR green, TaqMan probe, hybridization probes, molecular beacons, and microchip electrophoresis). Furthermore, there is no consensus on the optimal respiratory specimen to be used for M. pneumoniae detection by nucleic acid amplification tests and culture. Different specimens have been used, such as sputum, nasopharyngeal, or oropharyngeal swabs or washes; bronchoalveolar lavage; or pleural fluid. In a review on optimal sampling for the detection of respiratory pathogens, Loens et al. concluded that, if sputum is available, it might be the best specimen for M. pneumoniae detection by culture and NAATs. A nasopharyngeal swab, nasopharyngeal aspirate, or oropharyngeal swab might be the second best option for analysis by NAATs [50].

Interstudy variation is related to the reference diagnostic assay with which the new assay is compared (a serological test, culture, or a pre-existing PCR assay). Due to the lack of conformity between different studies, it is very difficult to compare the data from study to study.

Winchell et al. [51] evaluated three real-time PCR assays targeting the ATPase gene and newly described CARDS toxin genes during an M. pneumoniae outbreak. A total of 54 respiratory specimens from patients $(n=35)$ and controls $(n=19)$ were tested in triplicate with each PCR assay. The assay targeting the CARDS toxin gene proved to be the most sensitive (lower ct-values) in identifying positive 


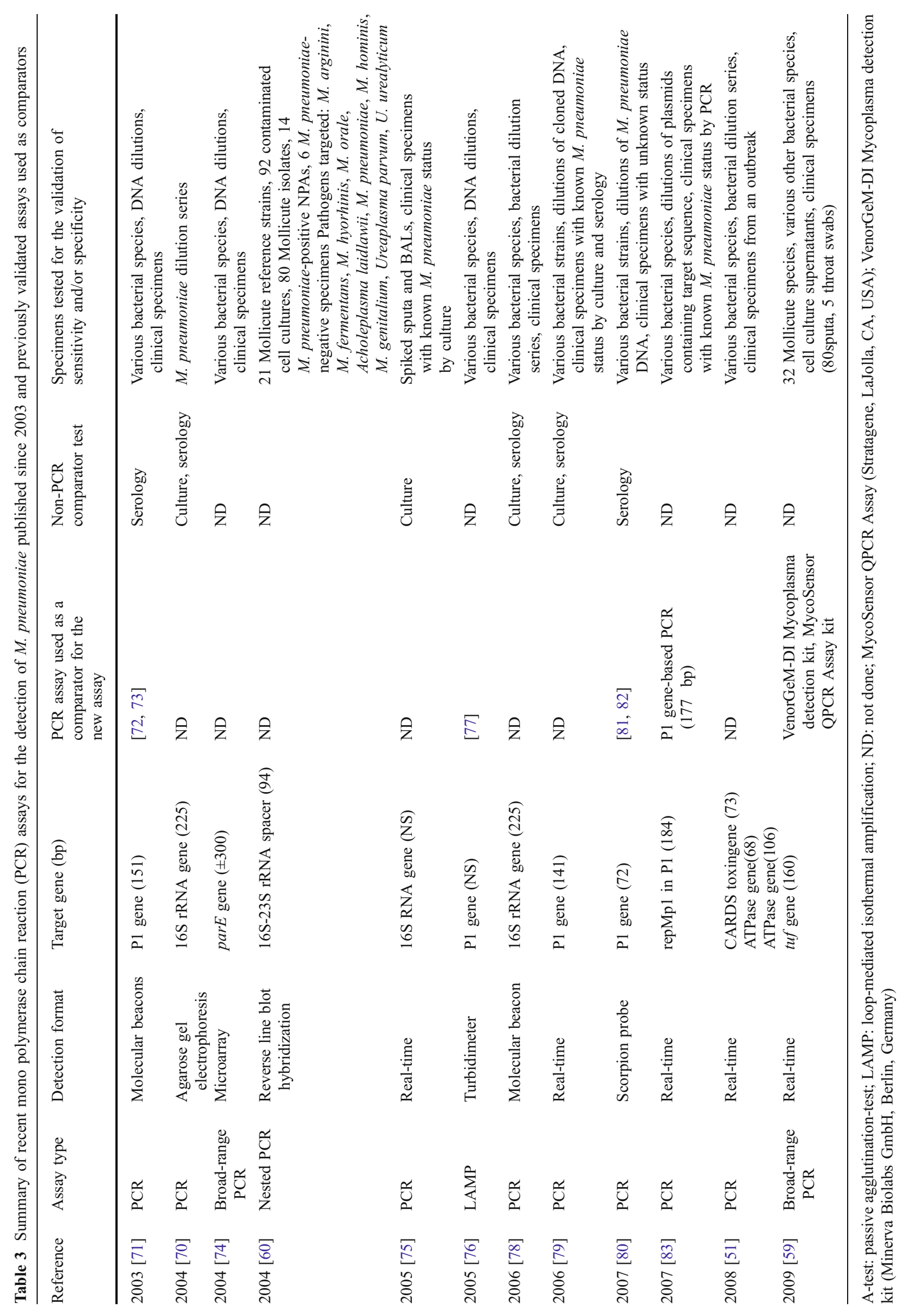




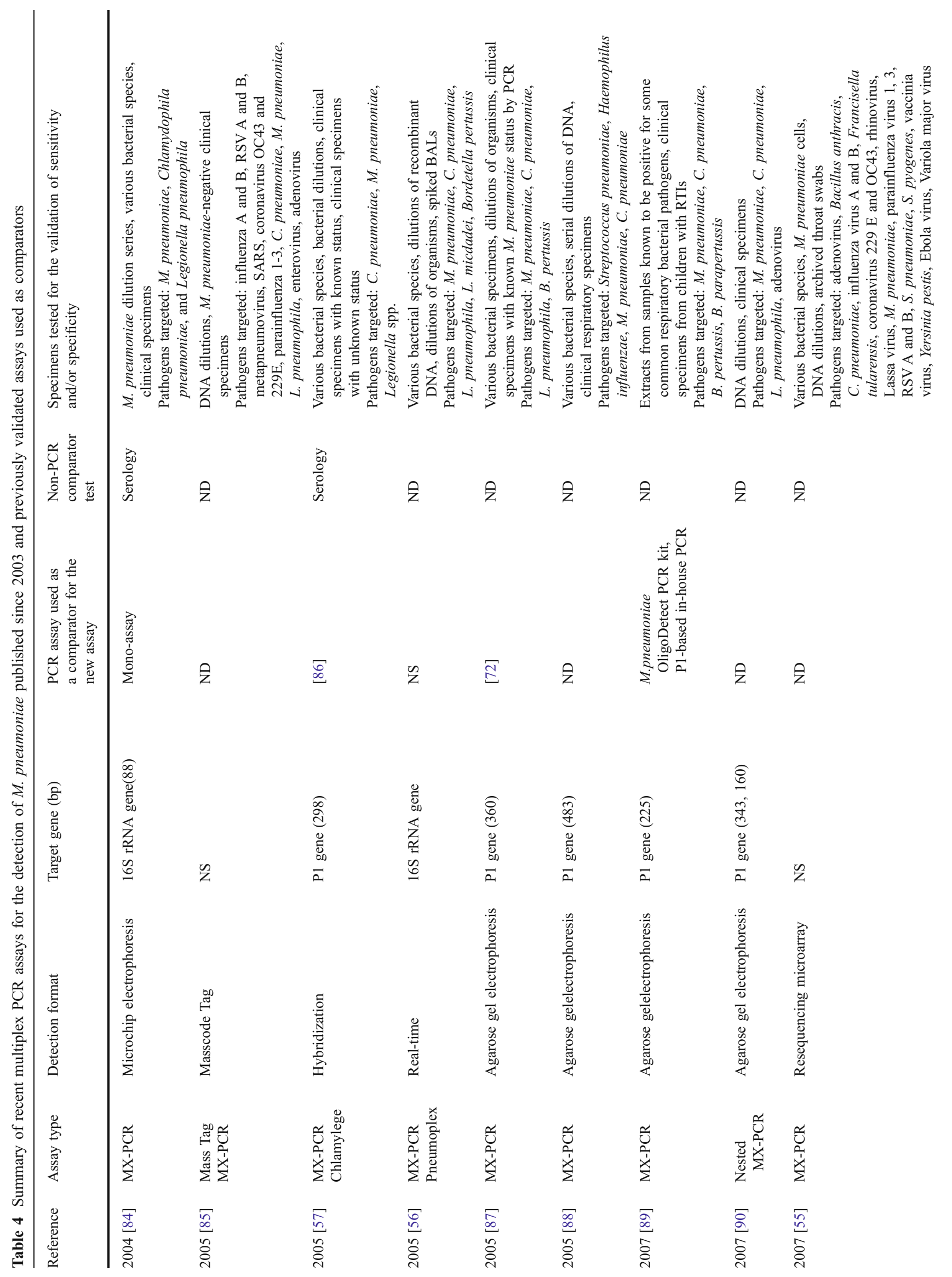



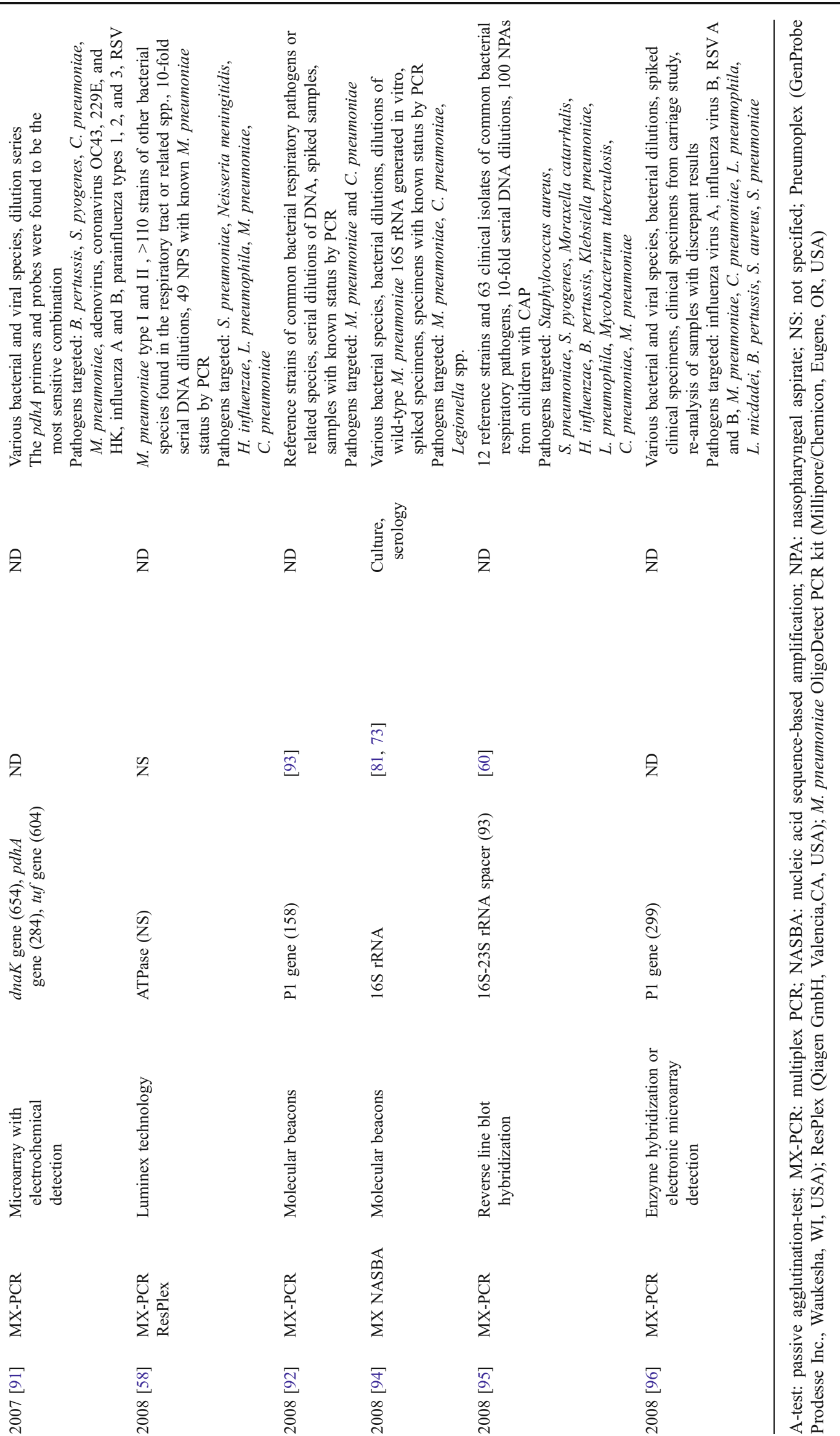

之

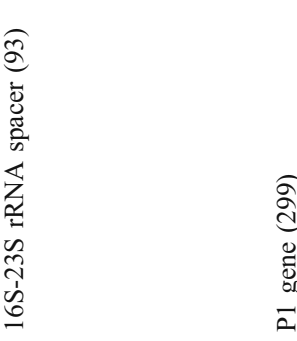

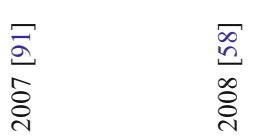

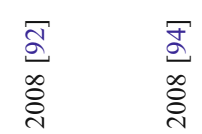

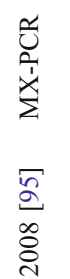

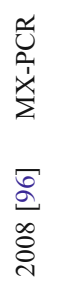


specimens. The analytical sensitivity of this assay was between 1-5 CFU, whereas it was between 5-50 CFU for the other two assays. However, the authors concluded that the inclusion of a second PCR assay may provide an increased level of confidence for the reporting of results. Dumke and Jacobs [52] compared under standardized conditions the performance of two commercial PCR assays (Artus RepMp1 [QIAGEN GmbH, Hilden, Germany] and the Venor Mp-QP M. pneumoniae kit [Minerva Biolabs $\mathrm{GmbH}$, Berlin, Germany] and three in-house PCR assays for the detection of $M$. pneumoniae on the LightCycler (Roche Diagnostics GmbH, Mannheim, Germany). All five procedures were able to demonstrate $M$. pneumoniae DNA in a concentration comparable to $1 \mathrm{CFU} / \mu \mathrm{l}$, but the differences in the mean crossing points between the tested procedures (up to 4.6) caused differences of the calculated mean concentration of the genome equivalents by a factor of up to 20 .

Multicenter studies that use a large and geographically diverse repertoire of clinical specimens and compare data from $>2$ centers independently are likely to provide important insights into the performance of new assays. To date, only two such studies describing multicenter comparisons of the performance of various NAATs for the detection of M. pneumoniae in respiratory specimens have been published, and both studies revealed significant variations of test performance from laboratory to laboratory $[2,53]$. Ursi et al. collected a panel of 78 respiratory samples from 43 patients which were analyzed in three different centers for the presence of M. pneumoniae DNA by different PCR assays [53]. Nucleic acids were extracted at one site and subsequently amplified in three centers. Loens et al. [2] used spiked respiratory specimens to compare the performance of several NAATs being used by 18 laboratories, each with their own extraction and amplification protocols. Both of these studies revealed significant intercenter discordance of detection rates, using different or even the same tests, despite the fact that the laboratories participating were very experienced with the use of PCR assays. In the spring of 2008, a pilot panel for the molecular diagnosis of $M$. pneumoniae was produced by Quality Control for Molecular Diagnostics (QCMD). An external quality assessment (EQA) panel consisting of a total of 13 samples in bronchoalveolar lavage (BAL) or transport medium were prepared to assess the proficiency of laboratories in the correct detection of Chlamydophila pneumoniae and Mycoplasma pneumoniae by NAATs (six samples containing various concentrations [4.9-490 inclusion forming units (IFU)/ml] of $C$. pneumoniae, five samples containing various concentrations $[20-5,000$ color changing units $(\mathrm{CCU}) / \mathrm{ml}]$ of $M$. pneumoniae, and two samples negative for both) [54]. Seventy-nine laboratories from 18 countries participated in this EQA study. Sixty- seven datasets were obtained for M. pneumoniae $(n=5$ conventional commercial, $n=10$ conventional in-house, $n=$ 4 real-time commercial, $n=46$ real-time in-house, $n=2$ strand displacement amplification [SDA]). For the total panel, correct results per sample varied between 53.7 and 95.5\% for M. pneumoniae.

Respiratory viruses and other so-called "atypical bacteria" are all responsible for RTIs that may produce clinically similar manifestations. In order to reduce costs and handson time, multiplex nucleic acid amplification techniques (MX-NAATs) have been developed (Table 4). Originally only two or three organisms were targeted in one assay. Currently, some assays detect up to 22 targets [55]. However, comparison between monoplex and multiplex assays has been rarely performed. Findings and conclusions result frequently in contradictory and conflicting data concerning the sensitivity and specificity of the MXNAATs compared to the monoplex NAAT. Owing to the complexity of the variables in a multiplex PCR, including different combinations of primer concentrations, magnesium ion concentrations, and annealing temperatures, this is not unexpected. The results of MX-NAATs on proficiency panels [2] seem to confirm that multiplex assays are somewhat less sensitive than monoplex assays, but until the number of organisms present in the clinical specimens of diseased individuals is known, it is impossible to state whether the degree of sensitivity attained is clinically acceptable.

It has been proposed that industry-produced assays in kit form may enable standardization. The Pneumoplex assay (Prodesse Inc.) (Table 4) was reported to have $100 \%$ sensitivity (when the sample contained $5 \mathrm{CFU} / \mathrm{ml}$ of $M$. pneumoniae) and $96 \%$ specificity for the detection of $M$. pneumoniae in spiked specimens [56]. The sensitivity of the Chlamylege assay (Argene Inc.) (Table 4) was $5.10^{-2} \mathrm{CCU}$ per reaction tube for M. pneumoniae [57]. A cohort of 154 clinical samples from patients with documented respiratory infections was analyzed by the same kit, including two samples from patients with C. pneumoniae infection, nine samples from patients with $M$. pneumoniae infection, 19 samples from patients with Legionella species infection, and 114 samples that tested negative for the three pathogens. All of the positive specimens were correctly detected and identified by the Chlamylege kit, and no falsepositive result was observed with the negative samples. The kit was then evaluated in a pediatric prospective study that included 220 endotracheal aspirates, and the results were compared with those obtained by three monoplex in-house PCR assays. Six specimens were found to be positive for $M$. pneumoniae by using both strategies. The Chlamylege kit detected two additional samples positive for M. pneumoniae. A comparative analysis of the limits of detection of the ResPlex I assay (Table 4) and real-time single PCR assays 
demonstrated that the ResPlex I assay is 10-fold less sensitive in detecting $M$. pneumoniae [58]. Furthermore, the ResPlex I assay was performed on 49 nasopharyngeal swab specimens known to be positive by real-time PCR for three pathogens (C. pneumoniae, M. pneumoniae, and S. pneumoniae) and detected 50, 59, and $81 \%$ of the C. pneumoniae-, $M$. pneumoniae-, and $S$. pneumoniae-positive samples, respectively. However, since the calculation of the sensitivities of the industry-produced multiplex assays was mainly dependent on the DNA copy number, further evaluation and standardization using an extended number of clinical specimens that may have a low load of the organism are needed.

There is also more and more a trend of adapting commercially available (e.g., MicroSeq Mycoplasma, Applied Biosystems) or in-house PCR assays for screening cell cultures for the presence of Mollicutes to respiratory specimens for the specific or generic detection of $M$. pneumoniae [59, 60]. These assays need to be extensively validated in terms of sensitivity and specificity as well before they can be applied to clinical respiratory specimens.

Ideally, a newly proposed NAAT assay should be validated by comparison with a sensitive culture system and at least one validated PCR or another NAAT assay that targets a different gene or a different sequence of the same gene.

Conventional manual nucleic acid extraction for the isolation of pathogen DNA or RNA from clinical samples is the most labor-intensive and critical part in current nucleic acid diagnostic assays. Automated nucleic acid extraction systems with high flexibilities in the type and numbers of samples to be handled, and with a wide range of sample input and elution volumes and short turnaround time will improve the application of NAATs to clinical services. Data from the literature indicate that the sensitivity of an NAAT after nucleic acid extraction with an automated system is similar to or better than the sensitivity after manual nucleic acid extraction. When the easyMAG nucleic acid extractor (bioMérieux) was applied retrospectively to clinical specimens, better amplification results were obtained for $M$. pneumoniae and $C$. pneumoniae detection compared with manual methods such as the Qiagen blood mini kit and the NucliSens miniMAG platform [61, 62]. This and other automated nucleic acid extraction instruments need to be further evaluated.

\section{Antibiotic resistance}

Since in 2001 a report was published describing the first macrolide-resistant $M$. pneumoniae strain possessing a $23 \mathrm{~S}$ rRNA gene mutation [63], other reports followed [64-67]. Although most macrolide-resistant strains were detected in Japan so far, the first macrolide-resistant M. pneumoniae strains in Europe were reported recently in France [68].
Since the impact of macrolide resistance on the outcome of the infections is not clear so far, measures need to be taken to identify these strains and PCR assays have been developed to detect some of these mutations [64, 69]. Both assays target the V-domain of the $23 \mathrm{~S}$ rRNA gene; the presence of point mutations in the amplicons is detected by using restriction fragment length polymorphism (RFLP) [64] or high-resolution melt curve analysis [69].

\section{Conclusions and future directions}

During recent years, significant progress has been made in the microbiological diagnosis of Mycoplasma pneumoniae respiratory tract infections (RTIs). Despite these many efforts, much is still unknown about the role of $M$. pneumoniae in respiratory and other infections. Most Mycoplasma infections never have a microbiological diagnosis because rapid, sensitive, and specific methods for its direct detection are not readily available in physician offices or hospital laboratories.

Significant limitations continue to surround the accurate and reliable serological diagnosis of $M$. pneumoniae infection. These include the wide variation of the methods and diagnostic criteria used across studies, which results in the subsequent emergence of data that remain incomparable and often controversial because of discordant and, at times, incorrect methodologies used.

Numerous in-house PCR assays to detect M. pneumoniae have been developed. Proper validation and standardization are still often lacking, and quality control studies have revealed frequent deficiencies, resulting in both falsenegative and false-positive results $[2,54]$. Consequently, all newly developed tests must be submitted to extensive validation before their introduction in the molecular diagnostic laboratory. Validation must be performed at several levels, including sample preparation, amplification, and detection. Since respiratory samples often contain substances inhibiting amplification, special attention should be paid to the efficiency of the reaction with these samples. Once a test is validated, it should be further evaluated in proficiency testing programs. Whereas quality control is an essential part of quality assurance in molecular diagnostics, proficiency panels for the detection of $M$. pneumoniae are not readily available. They are urgently needed to allow meaningful comparisons between the results obtained in different laboratories.

In conclusion, the following standards should be followed by all laboratories when validating new tests for the detection of $M$. pneumoniae: (i) having the ability to apply a second PCR at another target to at least some cases in epidemic situations; (ii) performing proficiency testing regularly in a blind fashion to ensure proper test and 
personnel performance; and (iii) incorporating hierarchical acceptance criteria monitoring for test failures, including positive and negative controls, re-evaluating multiple consecutive positive specimens, and confirming that positive specimens were collected from persons meeting the clinical case definition. Furthermore, multicenter studies that use a large and geographically diverse repertoire of clinical specimens and compare data from $>2$ centers independently are likely to provide important insights into the performance of new assays.

Given the high sensitivity and specificity of nucleic acidamplification techniques (NAATs), NAATs are the preferred diagnostic procedures for the diagnosis of $M$. pneumoniae infections, provided that the quality of the procedures is controlled. Additional prospective multicenter studies on large numbers of patients with respiratory signs and symptoms, including hospitalized and non-hospitalized patients, are necessary to extend our knowledge on the epidemiology of M. pneumoniae.

Acknowledgments Katherine Loens is supported through Priority 1 (Life Sciences, Genomics and Biotechnology for Health) of European Union's Sixth Framework Programme (FP6), contract number: LSHM-CT-2005-518226, GRACE.

\section{References}

1. Loens K, Ursi D, Goossens H, Ieven M (2003) Molecular diagnosis of Mycoplasma pneumoniae respiratory tract infections. J Clin Microbiol 41:4915-4923

2. Loens K, Beck T, Ursi D, Pattyn S, Goossens H, Ieven M (2006) Two quality control exercises involving nucleic acid amplification methods for detection of Mycoplasma pneumoniae and Chlamydophila pneumoniae and carried out 2 years apart (in 2002 and 2004). J Clin Microbiol 44:899-908

3. Dowell SF, Peeling RW, Boman J, Carlone GM, Fields BS, Guarner J, Hammerschlag MR, Jackson LA, Kuo CC, Maass M, Messmer TO, Talkington DF, Tondella ML, Zaki SR (2001) Standardizing Chlamydia pneumoniae assays: recommendations from the Centers for Disease Control and Prevention (USA) and the Laboratory Centre for Disease Control (Canada). Clin Infect Dis 33:492-503

4. Foy HM (1993) Infections caused by Mycoplasma pneumoniae and possible carrier state in different populations of patients. Clin Infect Dis 17(Suppl 1):S37-S46

5. Mundy LM, Auwaerter PG, Oldach D, Warner ML, Burton A, Vance E, Gaydos CA, Joseph JM, Gopalan R, Moore RD (1995) Community-acquired pneumonia: impact of immune status. Am J Respir Crit Care Med 152:1309-1315

6. van Kuppeveld FJ, Johansson KE, Galama JM, Kissing J, Bölske G, Hjelm E, van der Logt JT, Melchers WJ (1994) 16S rRNA based polymerase chain reaction compared with culture and serological methods for diagnosis of Mycoplasma pneumoniae infection. Eur J Clin Microbiol Infect Dis 13:401-405

7. Nagalingam NA, Adesiyun AA, Swanston WH, Bartholomew M (2004) Prevalence of Mycoplasma pneumoniae and Chlamydia pneumoniae in pneumonia patients in four major hospitals in Trinidad. New Microbiol 27:345-351
8. Oosterheert JJ, van Loon AM, Schuurman R, Hoepelman AI, Hak E, Thijsen S, Nossent G, Schneider MM, Hustinx WM, Bonten MJ (2005) Impact of rapid detection of viral and atypical bacterial pathogens by real-time polymerase chain reaction for patients with lower respiratory tract infection. Clin Infect Dis 41:1438-1444

9. Don M, Fasoli L, Paldanius M, Vainionpää R, Kleemola M, Räty R, Leinonen M, Korppi M, Tenore A, Canciani M (2005) Aetiology of community-acquired pneumonia: serological results of a paediatric survey. Scand J Infect Dis 37:806-812

10. Lehtinen P, Jartti T, Virkki R, Vuorinen T, Leinonen M, Peltola V, Ruohola A, Ruuskanen O (2006) Bacterial coinfections in children with viral wheezing. Eur J Clin Microbiol Infect Dis 25:463-469

11. Shenoy VD, Upadhyaya SA, Rao SP, Shobha KL (2005) Mycoplasma pneumoniae infection in children with acute respiratory infection. J Trop Pediatr 51:232-235

12. Gruteke P, Glas AS, Dierdorp M, Vreede WB, Pilon JW, Bruisten SM (2004) Practical implementation of a multiplex PCR for acute respiratory tract infections in children. J Clin Microbiol 42:55965603

13. Liu G, Talkington DF, Fields BS, Levine OS, Yang Y, Tondella ML (2005) Chlamydia pneumoniae and Mycoplasma pneumoniae in young children from China with community-acquired pneumonia. Diagn Microbiol Infect Dis 52:7-14

14. Gaillat J, Flahault A, deBarbeyrac B, Orfila J, Portier H, Ducroix JP, Bébéar C, Mayaud C (2005) Community epidemiology of Chlamydia and Mycoplasma pneumoniae in LRTI in France over 29 months. Eur J Epidemiol 20:643-651

15. Maltezou HC, La-Scola B, Astra H, Constantopoulou I, Vlahou V, Kafetzis DA, Constantopoulos AG, Raoult D (2004) Mycoplasma pneumoniae and Legionella pneumophila in community-acquired lower respiratory tract infections among hospitalized children: diagnosis by real time PCR. Scand J Infect Dis 36:639-642

16. Schneeberger PM, Dorigo-Zetsma JW, van der Zee A, van Bon M, van Opstal JL (2004) Diagnosis of atypical pathogens in patients hospitalized with community-acquired respiratory infection. Scand J Infect Dis 36:269-273

17. Sidal M, Kilic A, Unuvar E, Oguz F, Onel M, Agacfidan A, Aydin D, Koksalan K, Beka H (2007) Frequency of Chlamydia pneumoniae and Mycoplasma pneumoniae infections in children. J Trop Pediatr 53:225-231

18. Strålin K, Törnqvist E, Kaltoft MS, Olcén P, Holmberg H (2006) Etiologic diagnosis of adult bacterial pneumonia by culture and PCR applied to respiratory tract samples. J Clin Microbiol 44:643-645

19. van de Garde EM, Endeman H, van Hemert RN, Voorn GP, Deneer VH, Leufkens HG, van den Bosch JM, Biesma DH (2008) Prior outpatient antibiotic use as predictor for microbial aetiology of community-acquired pneumonia: hospital-based study. Eur J Clin Pharmacol 64:405-410

20. Yamazaki T, Narita M, Sasaki N, Kenri T, Arakawa Y, Sasaki T (2006) Comparison of PCR for sputum samples obtained by induced cough and serological tests for diagnosis of Mycoplasma pneumoniae infection in children. Clin Vaccine Immunol 13:708710

21. Kogan R, Martínez MA, Rubilar L, Payá E, Quevedo I, Puppo H, Girardi G, Castro-Rodriguez JA (2003) Comparative randomized trial of azithromycin versus erythromycin and amoxicillin for treatment of community-acquired pneumonia in children. Pediatr Pulmonol 35:91-98

22. Loens K, Beck T, Ursi D, Overdijk M, Sillekens P, Goossens H, Ieven M (2008) Evaluation of different nucleic acid amplification techniques for the detection of $M$. pneumoniae, C. pneumoniae and Legionella spp. in respiratory specimens from patients with community-acquired pneumonia. J Microbiol Methods 73:257262 
23. Miyashita N, Ouchi K, Kawasaki K, Oda K, Kawai Y, Shimizu H, Kobashi Y, Oka M (2008) Mycoplasma pneumoniae pneumonia in the elderly. Med Sci Monit 14:CR387-CR391

24. Ozaki T, Nishimura N, Ahn J, Watanabe N, Muto T, Saito A, Koyama N, Nakane K, Funahashi K (2007) Utility of a rapid diagnosis kit for Mycoplasma pneumoniae pneumonia in children, and the antimicrobial susceptibility of the isolates. J Infect Chemother 13:204-207

25. Shankar EM, Kumarasamy N, Balakrishnan P, Saravanan S, Solomon S, Vengatesan A, Murugavel KG, Rao UA (2007) Detection of pulmonary Mycoplasma pneumoniae infections in HIV-infected subjects using culture and serology. Int J Infect Dis 11:232-238

26. Creer DD, Dilworth JP, Gillespie SH, Johnston AR, Johnston SL, Ling C, Patel S, Sanderson G, Wallace PG, McHugh TD (2006) Aetiological role of viral and bacterial infections in acute adult lower respiratory tract infection (LRTI) in primary care. Thorax 61:75-79

27. Martínez TM, Pino PY, Salazar BT, Jover LE, Caroca CC, Espinoza NM, Avendaño CL (2005) Diagnostic utility of the polymerase chain reaction for the diagnosis of Mycoplasma pneumoniae in elderly patients with community-acquired pneumonia. Rev Chilena Infectol 22:251-256

28. Nilsson AC, Björkman P, Persson K (2008) Polymerase chain reaction is superior to serology for the diagnosis of acute Mycoplasma pneumoniae infection and reveals a high rate of persistent infection. BMC Microbiol 8:93

29. Menéndez R, Córdoba J, de La Cuadra P, Cremades MJ, LópezHontagas JL, Salavert M, Gobernado M (1999) Value of the polymerase chain reaction assay in noninvasive respiratory samples for diagnosis of community-acquired pneumonia. Am J Respir Crit Care Med 159:1868-1873

30. Beersma MF, Dirven K, van Dam AP, Templeton KE, Claas EC, Goossens H (2005) Evaluation of 12 commercial tests and the complement fixation test for Mycoplasma pneumoniae-specific immunoglobulin $\mathrm{G}$ (IgG) and IgM antibodies, with PCR used as the "gold standard". J Clin Microbiol 43:2277-2285

31. Otomo S, Yamamura J, Hayashi E, Nakamura T, Kakinuma H, Nakamoto Y, Takahashi H, Karasawa T (2008) Analysis of children with Chlamydophila (Chlamydia) pneumoniae and Mycoplasma pneumoniae respiratory infections by real-time PCR assay and serological tests. APMIS 116:477-483

32. Michelow IC, Olsen K, Lozano J, Rollins NK, Duffy LB, Ziegler T, Kauppila J, Leinonen M, McCracken GH Jr (2004) Epidemiology and clinical characteristics of community-acquired pneumonia in hospitalized children. Pediatrics 113:701-707

33. Nir-Paz R, Michael-Gayego A, Ron M, Block C (2006) Evaluation of eight commercial tests for Mycoplasma pneumoniae antibodies in the absence of acute infection. Clin Microbiol Infect 12:685-688

34. Petitjean J, Vabret A, Gouarin S, Freymuth F (2002) Evaluation of four commercial immunoglobulin $\mathrm{G}$ (IgG)- and IgM-specific enzyme immunoassays for diagnosis of Mycoplasma pneumoniae infections. J Clin Microbiol 40:165-171

35. Talkington DF, Shott S, Fallon MT, Schwartz SB, Thacker WL (2004) Analysis of eight commercial enzyme immunoassay tests for detection of antibodies to Mycoplasma pneumoniae in human serum. Clin Diagn Lab Immunol 11:862-867

36. Gavranich JB, Chang AB (2005) Antibiotics for community acquired lower respiratory tract infections (LRTI) secondary to Mycoplasma pneumoniae in children. Cochrane Database Syst Rev (3):CD004875

37. Liu FC, Chen PY, Huang FL, Tsai CR, Lee CY, Lin CF (2008) Do serological tests provide adequate rapid diagnosis of Mycoplasma pneumoniae infection? Jpn J Infect Dis 61:397-399

38. Vikerfors T, Brodin G, Grandien M, Hirschberg L, Krook A, Pettersson CA (1988) Detection of specific IgM antibodies for the diagnosis of Mycoplasma pneumoniae infections: a clinical evaluation. Scand J Infect Dis 20:601-610

39. Murray PR, Baron EJ, Jorgensen JH, Pfaller MA, Yolken RH (2003) Manual of clinical microbiology, 8th edn. ASM Press, Washington

40. Skerrett SJ (1999) Diagnostic testing for community-acquired pneumonia. Clin Chest Med 20:531-548

41. Lieberman D, Lieberman D, Ben-Yaakov M, Shmarkov O, Gelfer Y, Varshavsky R, Ohana B, Lazarovich Z, Boldur I (2002) Serological evidence of Mycoplasma pneumoniae infection in acute exacerbation of COPD. Diagn Microbiol Infect Dis 44:1-6

42. Lieberman D, Lieberman D, Korsonsky I, Ben-Yaakov M, Lazarovich Z, Friedman MG, Dvoskin B, Leinonen M, Ohana B, Boldur I (2002) A comparative study of the etiology of adult upper and lower respiratory tract infections in the community. Diagn Microbiol Infect Dis 42:21-28

43. Watkins-Riedel T, Stanek G, Daxboeck F (2001) Comparison of SeroMP IgA with four other commercial assays for serodiagnosis of Mycoplasma pneumoniae pneumonia. Diagn Microbiol Infect Dis 40:21-25

44. Narita M (2005) Evaluation of ELISA kits for detection of Mycoplasma pneumoniae-specific IgG, IgA, IgM antibodies on the diagnosis of Mycoplasma pneumoniae infection in children. $\mathrm{J}$ Jap Assoc Infect Dis 79:457-463

45. Csángó PA, Pedersen JE, Hess RD (2004) Comparison of four Mycoplasma pneumoniae IgM-, IgG- and IgA-specific enzyme immunoassays in blood donors and patients. Clin Microbiol Infect 10:1094-1098

46. Dorigo-Zetsma JW, Zaat SA, Wertheim-van Dillen PM, Spanjaard L, Rijntjes J, van Waveren G, Jensen JS, Angulo AF, Dankert J (1999) Comparison of PCR, culture, and serological tests for diagnosis of Mycoplasma pneumoniae respiratory tract infection in children. J Clin Microbiol 37:14-17

47. Waris ME, Toikka P, Saarinen T, Nikkari S, Meurman O, Vainionpää R, Mertsola J, Ruuskanen O (1998) Diagnosis of Mycoplasma pneumoniae pneumonia in children. J Clin Microbiol 36:3155-3159

48. Morton HE, Smith PF, Leberman PR (1951) Investigation of the cultivation of pleuropneumonia-like organisms from man. Am J Syph Gonorrhea Vener Dis 35:361-369

49. Edward DGF (1947) A selective medium for pleuropneumonialike organisms. J Gen Microbiol 1:238-243

50. Loens K, Van Heirstraeten L, Malhotra-Kumar S, Goossens H, Ieven M (2009) Optimal sampling sites and methods for detection of pathogens possibly causing community-acquired lower respiratory tract infections. J Clin Microbiol 47:21-31

51. Winchell JM, Thurman KA, Mitchell SL, Thacker WL, Fields BS (2008) Evaluation of three real-time PCR assays for detection of Mycoplasma pneumoniae in an outbreak investigation. J Clin Microbiol 46:3116-3118

52. Dumke R, Jacobs E (2009) Comparison of commercial and inhouse real-time PCR assays used for detection of Mycoplasma pneumoniae. J Clin Microbiol 47:441-444

53. Ursi D, Ieven $M$, Noordhoek GT, Ritzler $M$, Zandleven $H$, Altwegg M (2003) An interlaboratory comparison for the detection of Mycoplasma pneumoniae in respiratory samples by the polymerase chain reaction. J Microbiol Methods 53:289-294

54. Loens K, MacKay WG, Scott C, Goossens H, Wallace P, Ieven M (2010) A multicenter pilot external quality assessment programme to assess the quality of molecular detection of Chlamydophila pneumoniae and Mycoplasma pneumoniae. J Microbiol Methods (in press)

55. Lin B, Blaney KM, Malanoski AP, Ligler AG, Schnur JM, Metzgar D, Russell KL, Stenger DA (2007) Using a resequencing microarray as a multiple respiratory pathogen detection assay. $\mathrm{J}$ Clin Microbiol 45:443-452 
56. Khanna M, Fan J, Pehler-Harrington K, Waters C, Douglass P, Stallock J, Kehl S, Henrickson KJ (2005) The pneumoplex assays, a multiplex PCR-enzyme hybridization assay that allows simultaneous detection of five organisms, Mycoplasma pneumoniae, Chlamydia (Chlamydophila) pneumoniae, Legionella pneumophila, Legionella micdadei, and Bordetella pertussis, and its realtime counterpart. J Clin Microbiol 43:565-571

57. Ginevra C, Barranger C, Ros A, Mory O, Stephan JL, Freymuth F, Joannès M, Pozzetto B, Grattard F (2005) Development and evaluation of Chlamylege, a new commercial test allowing simultaneous detection and identification of Legionella, Chlamydophila pneumoniae, and Mycoplasma pneumoniae in clinical respiratory specimens by multiplex PCR. J Clin Microbiol 43:3247-3254

58. Benson R, Tondella ML, Bhatnagar J, Carvalho Mda G, Sampson JS, Talkington DF, Whitney AM, Mothershed E, McGee L, Carlone G, McClee V, Guarner J, Zaki S, Dejsiri S, Cronin K, Han J, Fields BS (2008) Development and evaluation of a novel multiplex PCR technology for molecular differential detection of bacterial respiratory disease pathogens. J Clin Microbiol 46:20742077

59. Störmer M, Vollmer T, Henrich B, Kleesiek K, Dreier J (2009) Broad-range real-time PCR assay for the rapid identification of cell-line contaminants and clinically important mollicute species. Int J Med Microbiol 299:291-300

60. Wang H, Kong F, Jelfs P, James G, Gilbert GL (2004) Simultaneous detection and identification of common cell culture contaminant and pathogenic mollicutes strains by reverse line blot hybridization. Appl Environ Microbiol 70:1483-1486

61. Loens K, Bergs K, Ursi D, Goossens H, Ieven M (2007) Evaluation of NucliSens easyMAG for automated nucleic acid extraction from various clinical specimens. J Clin Microbiol 45:421-425

62. Loens K, Ursi D, Goossens H, Ieven M (2008) Evaluation of the NucliSens miniMAG RNA extraction and real-time NASBA applications for the detection of Mycoplasma pneumoniae and Chlamydophila pneumoniae in throat swabs. J Microbiol Methods 72:217-219

63. Okazaki N, Narita M, Yamada S, Izumikawa K, Umetsu M, Kenri T, Sasaki Y, Arakawa Y, Sasaki T (2001) Characteristics of macrolide-resistant Mycoplasma pneumoniae strains isolated from patients and induced with erythromycin in vitro. Microbiol Immunol 45:617-620

64. Matsuoka M, Narita M, Okazaki N, Ohya H, Yamazaki T, Ouchi K, Suzuki I, Andoh T, Kenri T, Sasaki Y, Horino A, Shintani M, Arakawa Y, Sasaki T (2004) Characterization and molecular analysis of macrolide-resistant Mycoplasma pneumoniae clinical isolates obtained in Japan. Antimicrob Agents Chemother 48:4624-4630

65. Morozumi M, Hasegawa K, Kobayashi R, Inoue N, Iwata S, Kuroki H, Kawamura N, Nakayama E, Tajima T, Shimizu K, Ubukata K (2005) Emergence of macrolide-resistant Mycoplasma pneumoniae with a $23 \mathrm{~S}$ rRNA gene mutation. Antimicrob Agents Chemother 49:2302-2306

66. Morozumi M, Iwata S, Hasegawa K, Chiba N, Takayanagi R, Matsubara K, Nakayama E, Sunakawa K, Ubukata K (2008) Increased macrolide resistance of Mycoplasma pneumoniae in pediatric patients with community-acquired pneumonia. Antimicrob Agents Chemother 52:348-350

67. Suzuki S, Yamazaki T, Narita M, Okazaki N, Suzuki I, Andoh T, Matsuoka M, Kenri T, Arakawa Y, Sasaki T (2006) Clinical evaluation of macrolide-resistant Mycoplasma pneumoniae. Antimicrob Agents Chemother 50:709-712

68. Pereyre S, Charron A, Renaudin H, Bébéar C, Bébéar CM (2007) First report of macrolide-resistant strains and description of a novel nucleotide sequence variation in the P1 adhesin gene in
Mycoplasma pneumoniae clinical strains isolated in France over 12 years. J Clin Microbiol 45:3534-3539

69. Wolff BJ, Thacker WL, Schwartz SB, Winchell JM (2008) Detection of macrolide resistance in Mycoplasma pneumoniae by real-time PCR and high-resolution melt analysis. Antimicrob Agents Chemother 52:3542-3549

70. Morozumi M, Hasegawa K, Chiba N, Iwata S, Kawamura N, Kuroki H, Tajima T, Ubukata K (2004) Application of PCR for Mycoplasma pneumoniae detection in children with communityacquired pneumonia. J Infect Chemother 10:274-279

71. Templeton KE, Scheltinga SA, Graffelman AW, Van Schie JM, Crielaard JW, Sillekens P, van den Broek PJ, Goossens H, Beersma MF, Claas EC (2003) Comparison and evaluation of real-time PCR, real-time nucleic acid sequence-based amplification, conventional PCR, and serology for diagnosis of Mycoplasma pneumoniae. J Clin Microbiol 41:4366-4371

72. Ieven M, Ursi D, Van Bever H, Quint W, Niesters HG, Goossens H (1996) Detection of Mycoplasma pneumoniae by two polymerase chain reactions and role of $M$. pneumoniae in acute respiratory tract infections in pediatric patients. J Infect Dis 173:1445-1452

73. Loens K, Ieven M, Ursi D, Beck T, Overdijk M, Sillekens P, Goossens H (2003) Detection of Mycoplasma pneumoniae by real-time nucleic acid sequence-based amplification. J Clin Microbiol 41:4448-4450

74. Roth SB, Jalava J, Ruuskanen O, Ruohola A, Nikkari S (2004) Use of an oligonucleotide array for laboratory diagnosis of bacteria responsible for acute upper respiratory infections. J Clin Microbiol 42:4268-4274

75. Raggam RB, Leitner E, Berg J, Mühlbauer G, Marth E, Kessler HH (2005) Single-run, parallel detection of DNA from three pneumonia-producing bacteria by real-time polymerase chain reaction. J Mol Diagn 7:133-138

76. Saito R, Misawa Y, Moriya K, Koike K, Ubukata K, Okamura N (2005) Development and evaluation of a loop-mediated isothermal amplification assay for rapid detection of Mycoplasma pneumoniae. J Med Microbiol 54:1037-1041

77. Ursi D, Dirven K, Loens K, Ieven M, Goossens H (2003) Detection of Mycoplasma pneumoniae in respiratory samples by real-time PCR using an inhibition control. J Microbiol Methods $55: 149-153$

78. Morozumi M, Nakayama E, Iwata S, Aoki Y, Hasegawa K, Kobayashi R, Chiba N, Tajima T, Ubukata K (2006) Simultaneous detection of pathogens in clinical samples from patients with community-acquired pneumonia by real-time PCR with pathogenspecific molecular beacon probes. J Clin Microbiol 44:1440-1446

79. Pitcher D, Chalker VJ, Sheppard C, George RC, Harrison TG (2006) Real-time detection of Mycoplasma pneumoniae in respiratory samples with an internal processing control. J Med Microbiol 55:149-155

80. Di Marco E, Cangemi G, Filippetti M, Melioli G, Biassoni R (2007) Development and clinical validation of a real-time PCR using a uni-molecular Scorpion-based probe for the detection of Mycoplasma pneumoniae in clinical isolates. New Microbiol 30:415-421

81. Kong F, Gordon S, Gilbert GL (2000) Rapid-cycle PCR for detection and typing of Mycoplasma pneumoniae in clinical specimens. J Clin Microbiol 38:4256-4259

82. Sharma S, Brousseau R, Kasatiya S (1998) Detection and confirmation of Mycoplasma pneumoniae in urogenital specimens by PCR. J Clin Microbiol 36:277-280

83. Dumke R, Schurwanz N, Lenz M, Schuppler M, Lück C, Jacobs E (2007) Sensitive detection of Mycoplasma pneumoniae in human respiratory tract samples by optimized real-time PCR approach. J Clin Microbiol 45:2726-2730

84. Miyashita N, Saito A, Kohno S, Yamaguchi K, Watanabe A, Oda H, Kazuyama Y, Matsushima T (2004) Multiplex PCR for the 
simultaneous detection of Chlamydia pneumoniae, Mycoplasma pneumoniae and Legionella pneumophila in community-acquired pneumonia. Respir Med 98:542-550

85. Briese T, Palacios G, Kokoris M, Jabado O, Liu Z, Renwick N, Kapoor V, Casas I, Pozo F, Limberger R, Perez-Brena P, Ju J, Lipkin WI (2005) Diagnostic system for rapid and sensitive differential detection of pathogens. Emerg Infect Dis 11:310-313

86. de Barbeyrac B, Bernet-Poggi C, Fébrer F, Renaudin H, Dupon M, Bébéar C (1993) Detection of Mycoplasma pneumoniae and Mycoplasma genitalium in clinical samples by polymerase chain reaction. Clin Infect Dis 17(Suppl 1):S83-S89

87. McDonough EA, Barrozo CP, Russell KL, Metzgar D (2005) A multiplex PCR for detection of Mycoplasma pneumoniae, Chlamydophila pneumoniae, Legionella pneumophila, and Bordetella pertussis in clinical specimens. Mol Cell Probes 19:314-322

88. Strålin K, Bäckman A, Holmberg H, Fredlund H, Olcén P (2005) Design of a multiplex PCR for Streptococcus pneumoniae, Haemophilus influenzae, Mycoplasma pneumoniae and Chlamydophila pneumoniae to be used on sputum samples. APMIS 113:99-111

89. Geertsen R, Kaeppeli F, Sterk-Kuzmanovic N, Andrasevic S, AnicMilic T, Dobec M (2007) A multiplex PCR assay for the detection of respiratory bacteriae in nasopharyngeal smears from children with acute respiratory disease. Scand J Infect Dis 39:769-774

90. Lam WY, Yeung AC, Tang JW, Ip M, Chan EW, Hui M, Chan PK (2007) Rapid multiplex nested PCR for detection of respiratory viruses. J Clin Microbiol 45:3631-3640

91. Lodes MJ, Suciu D, Wilmoth JL, Ross M, Munro S, Dix K, Bernards K, Stöver AG, Quintana M, Iihoshi N, Lyon WJ, Danley
DL, McShea A (2007) Identification of upper respiratory tract pathogens using electrochemical detection on an oligonucleotide microarray. PLoS ONE 2:e924

92. Gullsby K, Storm M, Bondeson K (2008) Simultaneous detection of Chlamydophila pneumoniae and Mycoplasma pneumoniae by use of molecular beacons in a duplex real-time PCR. J Clin Microbiol 46:727-731

93. van Kuppeveld FJ, van der Logt JT, Angulo AF, van Zoest MJ, Quint WG, Niesters HG, Galama JM, Melchers WJ (1992) Genusand species-specific identification of mycoplasmas by 16S rRNA amplification. Appl Environ Microbiol 58:2606-2615

94. Loens K, Beck T, Ursi D, Overdijk M, Sillekens P, Goossens H, Ieven M (2008) Development of real-time multiplex nucleic acid sequence-based amplification for detection of Mycoplasma pneumoniae, Chlamydophila pneumoniae, and Legionella spp. in respiratory specimens. J Clin Microbiol 46:185-191

95. Wang Y, Kong F, Yang Y, Gilbert GL (2008) A multiplex PCRbased reverse line blot hybridization (mPCR/RLB) assay for detection of bacterial respiratory pathogens in children with pneumonia. Pediatr Pulmonol 43:150-159

96. Kumar S, Wang L, Fan J, Kraft A, Bose ME, Tiwari S, Van Dyke M, Haigis R, Luo T, Ghosh M, Tang H, Haghnia M, Mather EL, Weisburg WG, Henrickson KJ (2008) Detection of 11 common viral and bacterial pathogens causing community-acquired pneumonia or sepsis in asymptomatic patients by using a multiplex reverse transcription-PCR assay with manual (enzyme hybridization) or automated (electronic microarray) detection. J Clin Microbiol 46:3063-3072 